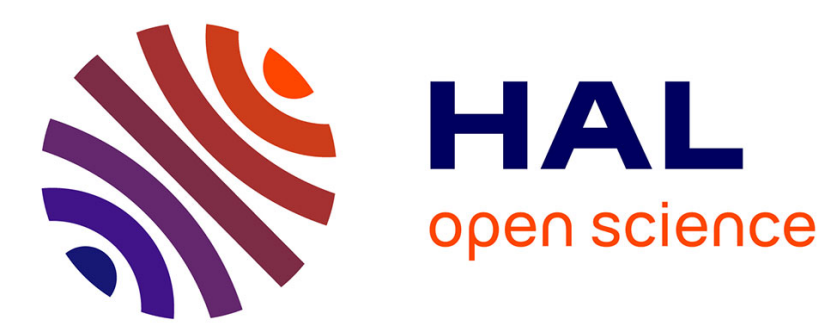

\title{
VIH et autres IST sur le grill
}

\author{
N. Dupin
}

\section{To cite this version:}

N. Dupin. VIH et autres IST sur le grill. Annales de Dermatologie et de Vénéréologie, 2019, 146, pp.A3 - A4. 10.1016/j.annder.2019.09.593 . hal-03488591

\section{HAL Id: hal-03488591 \\ https://hal.science/hal-03488591}

Submitted on 21 Dec 2021

HAL is a multi-disciplinary open access archive for the deposit and dissemination of scientific research documents, whether they are published or not. The documents may come from teaching and research institutions in France or abroad, or from public or private research centers.
L'archive ouverte pluridisciplinaire HAL, est destinée au dépôt et à la diffusion de documents scientifiques de niveau recherche, publiés ou non, émanant des établissements d'enseignement et de recherche français ou étrangers, des laboratoires publics ou privés.

\section{다)(1) $(5$}

Distributed under a Creative Commons Attribution - NonCommercial| 4.0 International 
ACTUALITÉS / Vendredi 06 décembre - 11h30 / 12h

VIH et autres IST sur le grill

\section{N Dupin}

Service de Dermatologie, Pavillon Tarnier, APHP.5, 75006 Paris

nicolas.dupin@aphp.fr

Les IST ou MST pour les nostalgiques sont, depuis 20 ans, redevenues un sujet d'actualité car en pleine recrudescence en commençant par la syphilis dite la grande simulatrice sans oublier les infections gonococciques et autre maladie de Nicolas Favre. Chaque année, Santé Publique France fait état de courbes ascensionnelles ou stables pour les différentes IST sans qu'on puisse envisager les prémices d'une inclinaison. Depuis 2004, la lutte contre le VIH et la lutte contre les IST ne font plus qu'un et les anciens dispensaires anti-vénériens ont acquis leur titre de centre de santé sexuelle, car le sexe ce n'est pas que les IST mais également tout ce qui touche à la sexualité. Il sera ici question de la syphilis, et des autres IST et des nouveaux moyens mis en place pour traiter le VIH et pour lutter contre l'épidémie de VIH. Il sera question de PrEP, de PEP et autres acronymes qui abritent des outils qui permettent d'envisager d'enrayer l'épidémie. Mais la tâche est rude, et les embuches se cachent parfois au décours des innovations, les IST et le VIH sont un tout et l'on ne peut dissocier les approches de prévention de l'un sans prendre en considération les risques qu'ils pourraient faire courir pour les autres. Prévenir les IST c'est toujours se protéger et par les temps qui courent, l'intérêt du préservatif est pour le moins sous-estimé.

\section{Publications :}

\section{Kaposi,}

Dupin, $\mathrm{N}$ et al. Lancet 1995

Dupin, N et al. PNAS 1999

Grange, $\mathrm{N}$ et al. J Invest Dermatology 2012

IST,

Van Haecke, C et al. Clin Infect Dis 2006

$P$ acnes,

Grange, P et al. Plos Pathogens 2009

Lheure, C et al. Plos One 2016

\section{Biographie}

Nicolas Dupin est PUPH de Dermatologie à Paris Descartes et dirige un groupe dans l'équipe de Biologie cutanée du Pr Sélim Aractingi à l'Institut Cochin (Unité Inserm 1016). Il a passé 2 ans comme visiting fellow dans le Laboratoire de Virologie de l'Institute of Cancer Research à Londres et est auteur de plus de 390 publications. Sa recherche est centrée sur les infections cutanées et les relations hôte-pathogène que ce soit dans le domaine des cancers viro-induits que dans l'inflammation cutanée ou les IST. Il est co-inventeur de 6 brevets 
d'innovation et est co-fondateur de la société SkinDermic, biotech spécialisée dans le domaine de thérapeutique dermatologique.

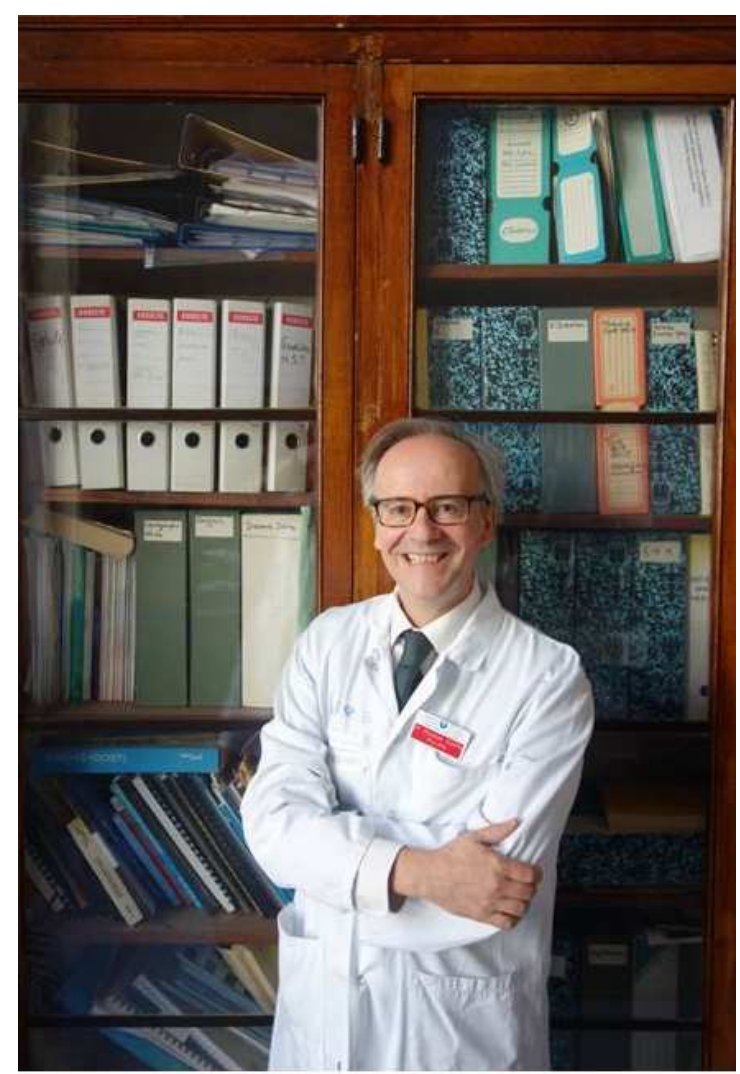

